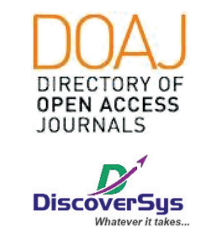

Published by DiscoverSys

\title{
Analisis faktor risiko infeksi malaria sesudah bencana gempa bumi di Kabupaten Lombok Barat, Indonesia
}

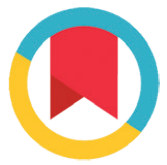

CrossMark

\author{
Michelle Amazing Grace Rampengan, ${ }^{1 *}$ Ni Made Utami Dwipayanti, ${ }^{1}$ \\ Putu Cintya Denny Yuliyatni ${ }^{1,2}$
}

\section{ABSTRACT}

Background: Malaria is an infectious disease that often arises in post-disaster situations such as earthquakes. The earthquake that occurred in Lombok caused damage to peopless homes and forced them to live in emergency tents. This condition increases the risk of malaria transmission so that malaria outbreak occurs. This study aims to determine the risk factors for malaria infection after the earthquake disaster in West Lombok Regency.

Methods: A case-control study was conducted among 168 respondents located in four Public Health Services working areas in West Lombok. Cases were positive malaria sufferers based on microscopic examination results and were recorded in the health centre register in the September-November 2018 period. In addition, the controls were people who did not suffer from malaria based on microscopic examination results and lived in the study area. Case samples were selected by systematic random sampling from the register of health centres and control samples were selected by convenient sampling from communities living in one hamlet with cases. The bivariate analysis uses Chi-Square and Fisher-Exact test, while multivariate analysis uses logistic regression in SPSS version 20 for Windows.

Results: The results showed that the proportion of male and female did not differ between groups of cases and controls $(50.0 \% ; p=1.00)$. Most of the case groups were $>34$ years old (51.8\%) while controls were $\leq 34$ years old (55.4\%). There were no differences in proportions at the level of education, occupation, type of residence, length of refuge, and location of refuge in the two groups $(p>0.05)$. The results of multivariate analysis showed that the risk factors for malaria infection after the earthquake disaster in the district of West Lombok were primarily due to the presence of gardens in refugee camps ( $A O R=$ 11,899; 95\% Cl: 2,369-59,774).

Conclusion: The existence of gardens in refugee camps is the most influential risk factor for malaria infection after the earthquake disaster in West Lombok Regency.

Keywords: Malaria, Risk Factors, Earthquake, West Lombok

Cite This Article: Rampengan, M.A.G., Dwipayanti, N.M.U., Yuliyatni, P.C.D. 2020. Analisis faktor risiko infeksi malaria sesudah bencana gempa bumi di Kabupaten Lombok Barat, Indonesia. Intisari Sains Medis 11(1): 357-363. D0I: 10.15562/ism.v11i1.660

'Program Studi Magister IImu Kesehatan Masyarakat, Fakultas Kedokteran, Universitas Udayana, Bali, Indonesia

2Departemen Kesehatan Masyarakat dan Kedokteran Pencegahan, Fakultas Kedokteran, Universitas Udayana, Bali, Indonesia

*Korespodensi Penulis: Michelle Amazing Grace Rampengan; Program Studi Magister IImu Kesehatan Masyarakat, Fakultas Kedokteran, Universitas Udayana, Bali, Indonesia; michellerampengan@gmail.com

Diterima: 09-04-2019

Disetujui: $15-03-2020$

Diterbitkan: 01-04-2020

\section{ABSTRAK}

Latar Belakang: Malaria adalah penyakit menular yang sering muncul pada situasi sesudah bencana seperti gempa bumi. Gempa bumi yang terjadi di Lombok ini mengakibatkan kerusakan pada rumah-rumah warga dan mengharuskan mereka tinggal di tendatenda darurat. Kondisi ini meningkatkan risiko penularan malaria sehingga terjadi Kejadian Luar Biasa (KLB) malaria. Penelitian ini bertujuan untuk mengetahui faktor risiko infeksi malaria sesudah bencana gempa bumi di Kabupaten Lombok Barat.

Metode: Penelitian kasus-kontrol (case-control) dan berlokasi di empat wilayah kerja puskesmas di Kabupaten Lombok Barat sebanyak 168 responden dilakukan pada penelitian ini. Kasus adalah penderita malaria positif berdasarkan hasil pemeriksaan mikroskopis dan tercatat dalam buku register puskesmas pada periode September-November 2018. Sedangkan kontrol adalah orang yang tidak menderita malaria berdasarkan hasil pemeriksaan mikroskopis dan tinggal di wilayah tempat penelitian. Sampel kasus dipilih secara systematic random sampling dari buku register puskesmas dan sampel kontrol dipilih secara convenient sampling dari masyarakat yang tinggal satu dusun dengan kasus. Analisis bivariat menggunakan chi square dan fisher sedangkan analisis multivariat menggunakan regresi logistik pada SPSS versi 20 untuk Windows.

Hasil: Hasil penelitian menunjukkan bahwa proporsi jenis kelamin laki-laki dan perempuan tidak berbeda antar kelompok kasus dan kontrol $(50,0 \% ; p=1,00)$. Sebagian besar kelompok kasus berusia $>34$ tahun (51,8\%) sedangkan kontrol berusia $\leq 34$ tahun (55,4\%). Tidak terdapat perbedaan proporsi pada tingkat pendidikan, pekerjaan, jenis tempat tinggal, lama mengungsi, dan lokasi mengungsi pada kedua kelompok ( $>00,05)$. Hasil analisis multivariat menunjukkan bahwa faktor risiko infeksi malaria sesudah bencana gempa bumi di kabupaten Lombok Barat adalah sebagian besar oleh keberadaan kebun di lokasi pengungsian (AOR=11,899; 95\%IK: 2,369-59,774). Simpulan: Keberadaan kebun di lokasi pengungsian merupakan faktor risiko yang paling berpengaruh terhadap infeksi malaria sesudah bencana gempa bumi di Kabupaten Lombok barat. 
Kata kunci: Malaria, Faktor Risiko, Gempa Bumi, Lombok Barat

Cite Pasal Ini: Rampengan, M.A.G., Dwipayanti, N.M.U., Yuliyatni, P.C.D. 2020. Analisis faktor risiko infeksi malaria sesudah bencana gempa bumi di Kabupaten Lombok Barat, Indonesia. Intisari Sains Medis 11(1): 357-363. D0I: 10.15562/ism.v11i1.660

\section{PENDAHULUAN}

Malaria adalah penyakit infeksi yang disebabkan oleh parasit plasmodium, yaitu $P$. falciparum, P. ovale, P. malariae, P. vivax dan P. knowlesi. ${ }^{1}$ Malaria ditularkan melalui gigitan nyamuk Anopheles betina yang infektif. ${ }^{2}$ Kasus malaria paling banyak ditemukan di Afrika dan India. ${ }^{3}$ Prevalensi malaria di Indonesia sebesar $0,37 \%$ hingga $17 \%$ tergantung daerah endemisnya. ${ }^{4}$ Malaria merupakan salah satu penyakit yang sering muncul pada situasi sesudah bencana terlebih di daerah endemis malaria dan berpotensi menimbulkan KLB. ${ }^{5,6}$

Pada tanggal 5 Agustus 2018, terjadi gempa bumi di Kabupaten Lombok dimana hal ini mengakibatkan kerusakan pada rumah-rumah warga sehingga mengharuskan masyarakat mengungsi di tenda-tenda darurat. ${ }^{7}$ Hampir semua tenda darurat yang ditinggali masyarakat tidak tertutup rapat dan lokasi pengungsian mereka dekat dengan habitat nyamuk Anopheles. ${ }^{8}$ Nyamuk Anopheles yang adalah vektor malaria suka menggigit manusia pada malam hari sehingga masyarakat yang tidur malam di tenda yang tidak tertutup rapat berisiko tinggi digigit nyamuk. ${ }^{9}$

Hasil kajian literatur menunjukkan bahwa faktor risiko infeksi malaria sesudah bencana adalah karakteristik masyarakat yang terkena dampak bencana, perubahan lingkungan akibat bencana, perilaku masyarakat yang terkena dampak bencana dan layanan kesehatan sesudah bencana. Penelitian sebelumnya yang dilakukan oleh Elsanousi YEA et al mengatakan insiden malaria tinggi pada kelompok umur $<5$ tahun setelah terjadi banjir di Sudan. ${ }^{10}$ Sedangkan Siahaan L dan Yuniarti $\mathrm{T}$ mengatakan penderita malaria paling banyak ditemukan pada kelompok umur 25-34 tahun dan 45-54 tahun pasca bencana tsunami di Aceh. ${ }^{11}$ Studi oleh Ding $G$ et al mengatakan genangan air akibat banjir meningkatkan populasi nyamuk dan berdampak pada insiden malaria di China. ${ }^{12}$ Saenz mengatakan perubahan perilaku masyarakat, yaitu tidur di luar pada malam hari meningkatkan risiko digigit nyamuk sehingga menimbulkan KLB malaria di Costa Rica setelah terjadi gempa bumi. ${ }^{13}$ Saenz juga mengatakan tertundanya pengendalian vektor karena terjadi gempa bumi merupakan salah satu faktor risiko KLB malaria di Costa Rica. ${ }^{13}$

Beberapa hasil kajian literatur tersebut berdasarkan situasi sesudah bencana di daerah lain yang berbeda dengan situasi bencana di Kabupaten Lombok Barat. Oleh sebab itu, masih terdapat knowledge gap tentang faktor risiko infeksi malaria sesudah bencana gempa bumi di Indonesia. Penelitian ini bertujuan untuk mengetahui faktor risiko infeksi malaria sesudah bencana gempa bumi khususnya di Kabupaten Lombok Barat.

\section{METODE}

Penelitian ini adalah penelitian observasional analitik menggunakan rancangan kasus kontrol. Lokasi penelitian di empat wilayah kerja puskesmas yang terjadi KLB malaria sesudah bencana gempa bumi di Kabupaten Lombok Barat, yaitu Puskesmas Sigerongan di Kecamatan Lingsar, Puskesmas Meninting di Kecamatan Batulayar, Puskesmas Penimbung dan Puskesmas Gunungsari di Kecamatan Gunungsari Kabupaten Lombok Barat. Pengumpulan data dilakukan pada bulan Juli 2019. Kasus adalah penderita malaria positif berdasarkan hasil pemeriksaan mikroskopis atau RDT, baru pertama kali terinfeksi malaria pada periode sesudah gempa bumi, ditemukan secara pasif di puskesmas, tercatat dalam buku register puskesmas pada tanggal 8 September-22 November 2018, berumur $\geq 15-55$ tahun dan tinggal di wilayah tempat penelitian. Kontrol adalah orang yang tidak menderita malaria berdasarkan hasil pemeriksaan mikroskopis atau RDT melalui kegiatan MBS pada periode sesudah gempa bumi, berumur $\geq 15-55$ tahun dan tinggal di wilayah tempat penelitian. Perbandingan kasus dan kontrol 1:2 dengan 56 kasus dan 112 kontrol. Sampel kasus dipilih secara sistematic random sampling dari buku register ke empat puskesmas dan sampel kontrol dipilih secara convenient sampling dari masyarakat yang tinggal satu dusun dengan kasus disesuaikan dengan kriteria kontrol. Kasus dan kontrol dimiripkan berdasarkan variabel jenis kelamin.

Data diambil dari hasil wawancara langsung dengan responden menggunakan kuesioner terstruktur. Data yang dikumpulkan adalah kondisi tempat tinggal responden sesudah bencana gempa bumi, kepadatan hunian, keberadaan habitat nyamuk Anopheles dilokasi tempat tinggal responden sesudah bencana gempa bumi (keberadaan kandang ternak, pohon besar, semak belukar, sawah, rawa, sungai dan kebun), perilaku perlindungan diri dari gigitan nyamuk (penggunaan kelambu, penggunaan obat anti nyamuk dan penggunaan penutup badan), karakteristik individu (umur dan pendidikan) dan layanan kesehatan sesudah bencana gempa bumi (jarak tempuh ke layanan kesehatan, 
waktu tempuh ke layanan kesehatan, pembagian kelambu, pembagian obat anti nyamuk, pelaksanaan fogging dan pemberian penyuluhan malaria). Data dianalisis secara bivariat menggunakan chi square dan fisher exact test serta multivariat menggunakan logistic regression dengan metode enter. Data yang telah diperoleh kemudian di analisis menggunakan SPSS versi 20 untuk Windows.

\section{HASIL}

Tabel 1 menunjukkan perbandingan antara kasus dan kontrol. Penelitian ini menunjukkan bahwa tidak terdapat perbedaan bermakna proporsi jenis kelamin laki-laki dan perempuan baik pada kelompok kasus dan kontrol $(50,0 \%)(\mathrm{p}=1,00)$. Berdasarkan kelompok usia, sebagian besar kelompok kasus berusia $>34$ tahun $(51,8 \%)$ dibandingkan dengan kelompok $\leq 34$ tahun $(55,4 \%)$ pada kelompok kontrol meskipun tidak berbeda bermakna $(p=0,38)$ (Tabel 1). Beberapa variabel yang diteliti pada responden penelitian baik pada kelompok kasus maupun kontrol menunjukkan bahwa sebagian besar responden memiliki tingkat pendidikan $\leq$ Sekolah Menengah Pertama (SMP), bekerja, tinggal di tenda darurat yang berlubang, tinggal di rumah dengan jenis dinding berupa tembok, berlantai semen, tidak berkawat kasa, mengungsi dalam rentang waktu $\leq 1$ bulan, dan lokasi mengungsi di halaman rumah meskipun tidak terdapat perbedaan yang bermakna $(p>0,05)$ (Tabel 1). Akan tetapi berdasarkan plafon tempat tinggal, sebagian besar kelompok kasus tidak memiliki plafon $(100,0 \%)$ sedangkan kelompok kontrol memiliki plafon tempat tinggal (66,7\%) meskipun tidak berbeda bermakna $(\mathrm{p}=1,000)$ (Tabel 1).

Tabel 2 menunjukkan nilai crude odds ratio (OR) berdasarkan analisis bivariat dari variabel-variabel yang masuk dalam analisis multivariat dan nilai adjusted odds ratio (AOR) berdasarkan analisis multivariat. Variabel yang merupakan faktor risiko infeksi malaria sesudah bencana gempa bumi di Kabupaten Lombok barat adalah keberadaan kebun di lokasi tempat tinggal dengan jarak < $1 \mathrm{~km}(\mathrm{AOR}=11,899$; 95\%IK: 2,369-59,774), kadang-kadang atau tidak pernah menggunakan baju lengan panjang selama mengungsi (AOR=2,871; 95\%IK: 1,222-6,746) dan tidak pernah mendapat penyuluhan malaria selama mengungsi $\quad(\mathrm{AOR}=9,919 ;$ 95\%IK: 3,178-30,963) (Tabel 2). Variabel yang memiliki nilai AOR paling besar adalah keberadaan kebun di lokasi tempat tinggal dengan jarak $<1 \mathrm{~km}$ (Tabel 2).

\section{Tabel 1 Perbandingan karakteristik responden penelitian pada kelompok kasus dan kontrol}

\begin{tabular}{|c|c|c|c|}
\hline \multirow[b]{2}{*}{ Karakteristik } & \multicolumn{2}{|c|}{ Responden Penelitian ( $\mathrm{N}=168$ ) } & \multirow[b]{2}{*}{$\boldsymbol{P}$} \\
\hline & Kasus $(\mathrm{N}=56)$ & Kontrol ( $\mathrm{N}=112)$ & \\
\hline \multicolumn{4}{|l|}{ Jenis kelamin, $\mathbf{n}(\%)$} \\
\hline Laki-laki & $28(50,0)$ & $56(50,0)$ & 1,00 \\
\hline Perempuan & $28(50,0)$ & $56(50,0)$ & \\
\hline \multicolumn{4}{|l|}{ Umur (tahun), n (\%) } \\
\hline$\leq 34$ & $27(48,2)$ & $62(55,4)$ & 0,38 \\
\hline$>34$ & $29(51,8)$ & $50(44,6)$ & \\
\hline \multicolumn{4}{|l|}{ Pendidikan, n (\%) } \\
\hline$\leq \mathrm{SMP}$ & $49(87,5)$ & $90(80,4)$ & 0,24 \\
\hline$>$ SMP & $7(12,5)$ & $22(19,6)$ & \\
\hline \multicolumn{4}{|l|}{ Pekerjaan, n (\%) } \\
\hline Tidak bekerja & $25(44,6)$ & $43(38,4)$ & 0,43 \\
\hline Bekerja & $31(55,4)$ & $69(61,6)$ & \\
\hline \multicolumn{4}{|c|}{ Jenis tempat tinggal, $\mathbf{n}(\%)$} \\
\hline \multicolumn{4}{|l|}{ Tenda darurat } \\
\hline Tidak berlubang & $3(5,6)$ & $8(7,3)$ & 1,00 \\
\hline Berlubang & $51(94,4)$ & $101(92,7)$ & \\
\hline \multicolumn{4}{|l|}{ Rumah } \\
\hline \multicolumn{4}{|l|}{ Jenis dinding } \\
\hline Tembok & $1(50,0)$ & $2(66,7)$ & 0,32 \\
\hline Bambu & $0(0,0)$ & $1(33,7)$ & \\
\hline Lainnya & $1(50,0)$ & $0(0,0)$ & \\
\hline
\end{tabular}


Tabel 1 Continue

\begin{tabular}{|c|c|c|c|}
\hline \multirow[b]{2}{*}{ Karakteristik } & \multicolumn{2}{|c|}{ Responden Penelitian ( $\mathrm{N}=168$ ) } & \multirow[b]{2}{*}{$\boldsymbol{P}$} \\
\hline & Kasus $(\mathrm{N}=56)$ & Kontrol ( $\mathrm{N}=112)$ & \\
\hline \multicolumn{4}{|l|}{ Jenis lantai } \\
\hline Semen & $2(100,0)$ & $2(66,7)$ & 1,00 \\
\hline Tanah & $0(0,0)$ & $1(33,3)$ & \\
\hline \multicolumn{4}{|l|}{ Plafon } \\
\hline Ada & $0(0,0)$ & $1(66,7)$ & 1,00 \\
\hline Tidak ada & $2(100)$ & $2(33,3)$ & \\
\hline \multicolumn{4}{|l|}{ Kawat kasa } \\
\hline Ada & $0(0,0)$ & $0(0,0)$ & - \\
\hline Tidak ada & $2(100,0)$ & $3(100,0)$ & \\
\hline \multicolumn{4}{|c|}{ Lama mengungsi, n (\%) } \\
\hline Tidak mengungsi & $9(16,1)$ & $12(10,7)$ & 0,42 \\
\hline$\leq 1$ bulan & $20(35,7)$ & $34(30,4)$ & \\
\hline 2 bulan & $13(23,2)$ & $23(20,5)$ & \\
\hline 3 bulan & $7(12,5)$ & $27(24,1)$ & \\
\hline$\geq 4$ bulan & $7(12,5)$ & $16(14,3)$ & \\
\hline \multicolumn{4}{|c|}{ Lokasi mengungsi, n (\%) } \\
\hline Tidak mengungsi & $9(16,1)$ & $12(10,7)$ & 0,64 \\
\hline Halaman rumah & $25(44,6)$ & $60(53,6)$ & \\
\hline Lapangan & $14(25,0)$ & $24(21,4)$ & \\
\hline Kebun & $8(14,3)$ & $16(14,3)$ & \\
\hline
\end{tabular}

Tabel 2 Crude Odds Ratio (OR) dan Adjusted Odds Ratio (AOR) Faktor Risiko Infeksi Malaria Sesudah Bencana Gempa Bumi di Kabupaten Lombok Barat

\begin{tabular}{|c|c|c|c|c|c|c|}
\hline Faktor Risiko & Crude OR & 95\%IK & $p$ & AOR & 95\%IK & $p$ \\
\hline \multicolumn{7}{|l|}{ Pendidikan } \\
\hline$\leq \mathrm{SMP}$ & 1,711 & $0,683-4,289$ & 0,24 & 1,210 & $0,363-4,040$ & 0,75 \\
\hline$>$ SMP & Ref & & & Ref & & \\
\hline \multicolumn{7}{|l|}{ Kandang ternak $(<1 \mathrm{~km})$} \\
\hline Ada & 1,494 & $0,782-2,856$ & 0,22 & 1,533 & $0,616-3,813$ & 0,35 \\
\hline Tidak ada & Ref & & & Ref & & \\
\hline \multicolumn{7}{|l|}{ Semak belukar $(<\mathbf{1 ~ k m})$} \\
\hline Ada & 3,841 & $1,090-13,535$ & 0,02 & 1,998 & $0,425-9,383$ & 0,38 \\
\hline Tidak ada & Ref & & & Ref & & \\
\hline \multicolumn{7}{|l|}{ Sawah $(<\mathbf{1 ~ k m )}$} \\
\hline Ada & 0,622 & $0,278-1,390$ & 0,24 & 0,493 & $0,176-1,381$ & 0,17 \\
\hline Tidak ada & Ref & & & Ref & & \\
\hline \multicolumn{7}{|l|}{$\operatorname{Kebun}(<1$ km) } \\
\hline Ada & 9,878 & $2,267-43,048$ & 0,00 & 11,899 & $2,369-59,774$ & 0,00 \\
\hline Tidak ada & Ref & & & Ref & & \\
\hline \multicolumn{7}{|c|}{ Penggunaan obat nyamuk oles } \\
\hline Kadang/tidak pernah & 3,068 & $1,438-6,548$ & 0,00 & 1,393 & $0,518-3,750$ & 0,51 \\
\hline Selalu & Ref & & & Ref & & \\
\hline
\end{tabular}


Tabel 2 Continue

\begin{tabular}{|c|c|c|c|c|c|c|}
\hline Faktor Risiko & Crude OR & 95\%IK & $p$ & AOR & 95\%IK & $p$ \\
\hline \multicolumn{7}{|c|}{ Penggunaan obat nyamuk bakar } \\
\hline Kadang/tidak pernah & 7,222 & $0,920-56,693$ & 0,03 & 4,315 & $0,439-42,364$ & 0,21 \\
\hline Selalu & Ref & & & Ref & & \\
\hline \multicolumn{7}{|l|}{ Penggunaan kelambu } \\
\hline Kadang/tidak pernah & 2,867 & $1,311-6,271$ & 0,00 & 2,601 & $0,794-8,518$ & 0,11 \\
\hline Selalu & Ref & & & Ref & & \\
\hline \multicolumn{7}{|c|}{ Penggunaan baju lengan panjang } \\
\hline Kadang/tidak pernah & 2,618 & $1,335-5,133$ & 0,00 & 2,871 & $1,222-6,746$ & 0,01 \\
\hline Selalu & Ref & & & Ref & & \\
\hline \multicolumn{7}{|l|}{ Pembagian kelambu } \\
\hline Tidak dapat & 2,888 & $1,484-5,263$ & 0,00 & 1,668 & $0,563-4,944$ & 0,35 \\
\hline Dapat & Ref & & & Ref & & \\
\hline \multicolumn{7}{|c|}{ Pembagian obat anti nyamuk } \\
\hline Tidak dapat & 2,549 & $1,191-5,459$ & 0,01 & 0,606 & $0,188-1,955$ & 0,40 \\
\hline Dapat & Ref & & & Ref & & \\
\hline \multicolumn{7}{|l|}{ Fogging } \\
\hline Tidak pernah & 2,912 & $1,130-7,502$ & 0,02 & 1,942 & $0,574-6,571$ & 0,28 \\
\hline Pernah & Ref & & & Ref & & \\
\hline \multicolumn{7}{|l|}{ Penyuluhan malaria } \\
\hline Tidak pernah & 5,597 & $2,214-14,147$ & 0,00 & 9,919 & $3,178-30,963$ & 0,00 \\
\hline Pernah & Ref & & & Ref & & \\
\hline
\end{tabular}

IK: interval kepercayaan; OR: odds ratio; AOR: adjusted odds ratio

\section{PEMBAHASAN}

Keberadaan kebun dengan jarak $<1 \mathrm{~km}$ dari lokasi pengungsian merupakan faktor risiko infeksi malaria sesudah bencana gempa bumi di Kabupaten Lombok Barat. Pada kondisi tidak bencana, keberadaan kebun di sekitar rumah juga terbukti sebagai faktor risiko kejadian malaria seperti pada hasil penelitian Handayani, Rubianti, dan Ernst. ${ }^{14-16}$ Keberadaan kebun dengan jarak $<1 \mathrm{~km}$ berpengaruh terhadap infeksi malaria. Kebun merupakan salah satu tempat peristirahatan nyamuk Anopheles dewasa yang eksofilik (lebih suka istirahat di luar ruangan) saat aktif mencari darah. ${ }^{17}$ Jarak terbang nyamuk Anopheles dewasa 1-3 km sehingga responden yang lokasi pengungsiannya berjarak $<1 \mathrm{~km}$ dari kebun memiliki risiko tinggi digigit nyamuk. ${ }^{17}$ Hal ini juga didukung dengan kondisi tenda darurat yang ditinggali responden, dimana hampir semua responden tinggal di tenda darurat yang tidak tertutup rapat. Kondisi tenda darurat yang tidak tertutup rapat memudahkan nyamuk masuk ke dalam tenda dan menggigit responden. Oleh sebab itu, upaya untuk meminimalisir paparan terhadap gigitan nyamuk harus menggunakan tenda yang tertutup rapat sesuai dengan standar tenda BNPB terlebih di daerah endemis malaria pada kondisi bencana. Petugas kesehatan pemegang program malaria harus segera melakukan upaya pengendalian vektor malaria seperti penyemprotan insektisida dan pembagian kelambu berinsektisida di lokasi pengungsian yang dekat dengan kebun ${ }^{(3)}$. Surveilans penyakit juga perlu dilakukan untuk meningkatkan kewaspadaan dini terhadap timbulnya kasus malaria pada masyarakat pengungsi yang lokasi pengungsiannya dekat dengan kebun. ${ }^{9}$

Pemakaian baju lengan panjang yang kadangkadang atau tidak pernah merupakan faktor risiko infeksi malaria sesudah bencana gempa bumi di Kabupaten Lombok Barat. Hasil ini sesuai dengan hasil penelitian Harmendo pada kondisi tidak bencana. ${ }^{18}$ Sejak terjadi bencana gempa bumi, responden menjadi lebih banyak beraktivitas di luar ruangan pada malam hari. Malam hari merupakan waktu nyamuk Anopheles menghisap darah karena pada malam hari udara cenderung lebih lembab. ${ }^{17}$ Perilaku responden yang kadang-kadang atau tidak pernah memakai baju lengan panjang saat malam hari membuat responden mudah digigit nyamuk Anopheles. Oleh sebab itu, petugas kesehatan harus 
memberikan informasi kepada semua masyarakat pengungsi terlebih di daerah endemis malaria untuk selalu memakai baju tertutup saat malam hari sebagai upaya perlindungan diri dari gigitan nyamuk Anopheles. ${ }^{9}$

Hasil penelitian ini menunjukkan bahwa infeksi malaria sesudah bencana gempa bumi di Kabupaten Lombok Barat lebih berisiko terjadi bila masyarakat tidak pernah mendapat penyuluhan malaria selama mengungsi. Hasil ini sejalan dengan hasil review yang dilakukan Pascapurnama DN et al, dimana pengetahuan masyarakat tentang kesehatan menentukan terjadinya penyakit menular pada kondisi bencana. ${ }^{19}$ Pada kondisi tidak bencana, ketidaktahuan tentang malaria juga terbukti sebagai faktor risiko kejadian malaria seperti hasil penelitian Rubianti. ${ }^{15}$ Sebagian besar responden tidak menggunakan obat anti nyamuk, kelambu dan pakaian tertutup saat malam hari selama mengungsi. Responden yang pada umumnya berpendidikan rendah kemungkinan besar tidak mengetahui kalau perilaku mereka yang seperti itu meningkatkan risiko terkena malaria. Pemberian penyuluhan akan sangat membantu meningkatkan pengetahuan responden serta dapat mempengaruhi perilaku responden untuk mengurangi risiko. Oleh karena itu, pemberian penyuluhan malaria sangat penting dilakukan pada semua masyarakat yang terkena dampak bencana terlebih khusus di daerah endemis malaria.

Penelitian ini adalah penelitian kasus kontrol dimana data mengenai pajanan terhadap faktor risiko diperoleh dengan mengandalkan daya ingat responden. Information bias kemungkinan terjadi karena responden yang termasuk kasus lebih mengingat pajanan terhadap faktor risiko dari pada responden yang termasuk kontrol.

\section{SIMPULAN}

Keberadaan kebun di lokasi pengungsian merupakan faktor risiko yang paling berpengaruh terhadap infeksi malaria sesudah bencana gempa bumi di Kabupaten Lombok barat. Penyuluhan tentang perilaku perlindungan diri dari gigitan nyamuk saat malam hari penting diberikan pada masyarakat yang mengungsi.

\section{PERSETUJUAN ETIK}

Penelitian ini telah mendapat persetujuan etik dari Komite Etik Fakultas Kedokteran Universitas Mataram sebelum penelitian ini dilakukan.

\section{KONFLIK KEPENTINGAN}

Penulis menyatakan bahwa tidak terdapat konflik kepentingan dalam penulisan artikel ini.

\section{PENDANAAN}

Penulis bertanggung jawab penuh terhadap pendanaan penelitian ini tanpa melibatkan pihak manapun.

\section{KONTRIBUSI PENULIS}

Seluruh penulis berkontribusi bersama dalam penyusunan artikel ini mulai dari penyusunan kerangka berpikir, pengumpulan data, analisis data penelitian, hingga interpretasi data dalam bentuk publikasi ilmiah.

\section{DAFTAR PUSTAKA}

1. Talapko J, Škrlec I, Alebić T, Jukić M, Včev A. Malaria: The Past and the Present. Microorganisms. 2019;7(6):179.

2. Dimopoulos G, Kafatos FC, Waters AP, Sinden RE. Malaria parasites and the anopheles mosquito. Chem Immunol. 2002;80:27-49.

3. Autino B, Noris A, Russo R, Castelli F. Epidemiology of malaria in endemic areas. Mediterr J Hematol Infect Dis. 2012;4(1):e2012060.

4. Elyazar IR, Hay SI, Baird JK. Malaria distribution, prevalence, drug resistance and control in Indonesia. Adv Parasitol. 2011;74:41-175.

5. Kouadio IK, Aljunid S, Kamigaki T, Hammad K, Oshitani H. Infectious diseases following natural disasters: prevention and control measures. Expert Rev Anti Infect Ther. 2012;10(1):95-104.

6. Lemonick DM. Epidemics After Natural Disasters. Am J Clin Med. 2011;8(3):144-52.

7. Dinas Kesehatan Provinsi NTB. Pelaporan Perkembangan Krisis Kesehatan Dinas. 2018.

8. Dinas Kesehatan Kabupaten Lombok Barat. Laporan KLB Malaria Di Kabupaten Lombok Barat. 2018.

9. Guelbéogo WM, Gonçalves BP, Grignard L, Bradley J, Serme SS, Hellewell J, et al. Variation in natural exposure to anopheles mosquitoes and its effects on malaria transmission. Elife. 2018;7:e32625.

10. Elsanousi YEA, Elmahi AS, Pereira I, Debacker M. Impact of the 2013 Floods on the Incidence of Malaria in Almanagil Locality, Gezira State, Sudan. PLoS Curr. 2018;10:ecurrents.dis.8267b8917b47bc12ff3a712fe4589fe1.

11. Siahaan L, Yuniarti T. Malaria Pasca Tsunami di Pulau Weh. Jurnal Kesehatan Masyarakat Nasional. 2008;2(5);210-214.

12. Ding G, Gao L, Li X, Zhou M, Liu Q, Ren H, et al. A mixed method to evaluate burden of malaria due to flooding and waterlogging in Mengcheng County, China: a case study. PLoS One. 2014;9(5):e97520.

13. Sáenz R, Bissell RA, Paniagua F. Post-disaster malaria in Costa Rica. Prehosp Disaster Med. 1995;10(3):154-160.

14. Handayani L, Pebrorizal, Soeyoko. Faktor Risiko Penularan Malaria Vivak. Berita Kedokteran Masyarakat. 2008;24(1):38-43.

15. Rubianti I, Wibowo TA, Solikhah. Faktor-Faktor Risiko Malaria Di Wilayah Kerja Puskesmas Paruga Kota Bima Nusa Tenggara Barat. Kes Mas: Jurnal Fakultas Kesehatan Masyarakat. 2009;3(3):162-232. 
16. Ernst KC, Lindblade KA, Koech D, Sumba PO, Kuwuor DO, John CC, et al. Environmental, socio-demographic and behavioural determinants of malaria risk in the western Kenyan highlands: a case-control study. Trop Med Int Health. 2009;14(10):1258-1265.

17. Sattler MA, Mtasiwa D, Kiama M, Premji Z, Tanner M, Killen GF, et al. Habitat characterization and spatial distribution of Anopheles sp. mosquito larvae in Dar es Salaam (Tanzania) during an extended dry period. Malar J. 2005;4:4.

18. Harmendo, Wahyuningsih NE, Raharjo M. Faktor Risiko Kejadian Malaria Di Wilayah Kerja Puskesmas Kenanga Kecamatan Sungailiat Kabupaten Bangka. Jurnal Kesehatan Lingkungan Indonesia. 2009;8(1):15-19.
19. Pascapurnama DN, Murakami A, Chagan-Yasutan H, Hattori T, Sasaki H, Egawa S. Integrated health education in disaster risk reduction : Lesson learned from disease outbreak following natural disasters in Indonesia. International Journal of Disaster Risk Reduction. 2018;29:94-102.

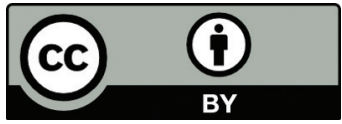

This work is licensed under a Creative Commons Attribution 